\title{
CIDADES: O HÁBITO DE HABITAR E OUTROS PONTOS
}

\author{
Maria Angélica Amâncio Santos*
}

Resumo: O objetivo deste ensaio é o de refletir sobre o hábito de habitar a partir da construção da cidade em pontilhamento, ou seja, busca-se na técnica artística do pontilhismo, tão afim à pintura impressionista, o modelo para se pensar a constituição do espaço urbano como uma imensa aglomeração de pontos - 0 bairro, a rua, a vizinhança, o edifício, o apartamento. Ao mesmo tempo, esse pontilhamento remeteria à delimitação das linhas pontilhadas, que, às vezes invisíveis às vezes traçadas por cercas, muros, paredes, separam os incontáveis cidadãos que habitam e atravessam esses locais. Desse modo, discute-se a influência do espaço nas relações humanas e das relações nos grandes espaços; além de analisar diferentes formas de conflito visíveis a partir do estudo de uma "vizinhança": xenofobia, processo migratório, aluguel, como veículo de transição e de transitoriedade. Para essa reflexão, parte-se de um corpus diversificado, pensando de que maneira cada uma dessas obras, em suas linguagens particulares, logra espelhar/debater determinadas práticas sociais. Tal corpus inclui o romance A vida modo de usar, de Georges Perec, o documentário Récits d'Ellis Island, do mesmo autor, além da graphic novel Avenida Dropsie: a vizinhança, de Will Eisner. Busca-se ainda o respaldo teórico de autores como Marc Augé, Walter Benjamin, Kevin Lynch e Henri Lefebvre.

Palavras-chave: Pontilhar; espaço urbano; habitar; vizinhança.

* Universidade Federal de Minas Gerais. 


\begin{abstract}
The purpose of this essay is to reflect on the habit of living, starting this thought from the construction of the city through dots, i.e., to search on the artistic technique of pointillism, so close to impressionist painting, the model for thinking the constitution of urban space as a huge agglomeration of points - the neighborhood, the street, the block, the building, the apartment. At the same time, this would refer to the delimitation of dotted lines, which, sometimes invisible sometimes drawn by fences, walls, separate the countless citizens who live and pass through these places. Thus, we discuss the influence of space in human relations and relationships in large spaces, and to analyze different forms of conflict visible from the study of a "neighborhood": xenophobia, migration process, the rent as a way of transition and of transience. For this reflection, we use a diversified corpus, thinking of how each of the works, in their particular languages, manages to reflect / discuss certain social practices. This corpus includes the romance La vie mode d'emploi, by Georges Perec, the documentary Récits d'Ellis Island, by the same author, in addition to the graphic novel Dropsie Avenue: the neigbborbood, by Will Eisner. The research has the theoretical support of authors such as Marc Augé, Walter Benjamin, Henri Lefebvre and Kevin Lynch.
\end{abstract}

Keywords: To dot; urban space; to live; neighborhood.

Habitar nem sempre foi um hábito. Por muito tempo, o homem viveu em deslocamento constante, fosse em razão das condições climáticas, fugindo de predadores ou perseguindo sua caça - esta que, por sua vez, também se movia em razão do tempo, do perigo ou à procura de alimentos. Naquele período, portanto, habitar era uma prática instável, representada muito mais pelo abrigo da caverna, que protegia da chuva, do vento e de certos animais ferozes. Era primordialmente uma questão de natureza, não de artifício. 
Com o desenvolvimento da agricultura, que se dá entre os anos 8.000 e 5.000 a.C., no Período Neolítico, o homem se sedentariza, passando a viver à beira de lagos e rios. Começa a domesticar animais e a constituir os primeiros conglomerados, fundamentados principalmente na expectativa de defesa. Nessa comunidade primitiva o solo ainda pertencia a todos. A partir daí, no entanto, transformam-se as relações familiares, ampliando-se o conceito de posse e de propriedade individual.

Desse momento em diante, habitar foi tornando-se cada vez mais complexo e, com uma naturalidade quase nunca questionada, cada vez mais obrigatório. Não é por acaso que a figura do morador de rua gere tamanho estranhamento sobre o "homem civilizado". Esquece-se este de suas origens nômades. Esquece-se de que alugar ou comprar uma casa pressupõe uma larga estrutura social, que inclui um emprego, um salário fixo, a possibilidade de arcar com outras necessidades que se fazem mais prementes, como a alimentação e o vestuário. Esquece-se de que é possível - ainda que pouco higiênico ou confortável - habitar as ruas, especialmente em uma comunidade em que as possibilidades de ascensão e manutenção social não se apresentam de maneira igualitária para todos.

Assim, o sentido de domicílio ainda se mantém como abrigo e proteção - agora, em grande parte, da criminalidade, inclusive daquela que se imagina praticável pelos "moradores de rua". Porém, o significado migra também, em essência disfarçada, para o de status, ostentação, prova material do dinheiro que se recebe, do cargo que se ocupa, da respeitabilidade. $\mathrm{O}$ andar em que se situa o apartamento, os metros quadrados, a altura dos muros, a beleza do jardim, a extensão da piscina, as idiossincrasias da arquitetura, o número dos cômodos, a localização, o preço do condomínio. E, claro, os interiores: a decoração, as obras de arte, o bom gosto. Todas são formas de exibição burguesa, de afirmação social. Mas, ao mesmo tempo, são maneiras de buscar o conforto, o bem-estar, a melhor condição de vida. 
Retorna-se, assim, à origem: nômade ou sedentário, o que move - ou paralisa - o homem não é justamente sua busca por melhores condições de vida?

\section{II}

Por diversos momentos, o homem precisou novamente deslocar-se - para outras cidades, estados, países, continentes no encalço de condições que o favorecessem. A esse processo deuse o nome de migração e raramente ele foi executado com simplicidade. Isso porque o nomadismo já deixara de ser parte fundamental da humanidade há muito tempo, fazendo com que o indivíduo realizasse outra sorte de mudança: a de um espaço fixo para outro. Deixa-se para trás, portanto, uma vida que, diferentemente do modelo anterior, estava estabelecida, em relação a uma família, a um grupo social, a um local de convívio e recordação. ${ }^{1} \mathrm{E}$ esforça-se por se adequar a outra realidade, cujos moldes - cultura, idioma, dogmas, expectativas - já estão claramente delimitados. O imigrante é, portanto, um sem-lugar. É o desconforto da bagagem, item cujas alças e o tamanho possibilitam a mobilidade, mas cujo peso e o conteúdo pressagiam o repouso, ainda que breve.

O documentário Récits d'Ellis Island, histoire d'errance et d'espoir, (1980), de Georges Perec e Robert Bober, confronta o espectador com esse sentimento de perplexidade, entre a partida e a chegada, diante do lugar de dispersão que representou Ellis Island, para tantos imigrantes que, a partir da primeira metade do século XIX, fugiam das dificuldades vividas na Europa rumo à América, terra virgem e teoricamente aberta a todos.

O filme é dividido em duas partes, "L'Ile des larmes" e "Mémoires", sendo a primeira delas filmada na própria ilha - hoje

${ }^{1}$ Ainda sobre o tema da segurança emocional da terra natal, cf. Lynch (1960, p. 5). 
aberta à visitação -, e a segunda tratando-se de uma reunião de três entrevistas com parentes desses imigrantes. Houve ainda a publicação do texto de Perec, mescla de prosa e poesia - do qual se retiram as frases aqui transcritas -, em três diferentes edições, duas das quais incluíam também as entrevistas e os documentos que constavam de seu diário de filmagem.

Segundo o autor, a abertura do centro de acolhimento Ellis Island, em 1892, marca o início de uma emigração oficial, institucionalizada, para essas quase dezesseis milhões de pessoas que tentavam entrar nos Estados Unidos.

Em suma, Ellis Island não será nada além de outra usina de fabricar americanos, uma usina para transformar emigrantes em imigrantes, uma usina à moda americana, tão rápida e eficaz quanto um açougue de Chicago: de um lado, se coloca um irlandês, um judeu ucraniano ou um italiano, e do outro - depois da inspeção dos olhos, inspeção dos bolsos, desinfecção - sai um americano. (PEREC, 1991, p. 15-16) ${ }^{2}$

De fato, como mostra a primeira parte do filme - que em muito se resume à filmagem da apresentação da ilha por um guarda fazendo as vezes de guia de turismo -, 70\% dos imigrantes vindos da Europa passavam por essa "usina de fabricar americanos". Só não se submetiam à inspeção aqueles que viajavam de primeira classe: o consenso era o de que, se alguém tinha dinheiro suficiente para pagar uma viagem assim, não seria portador de qualquer doença, sendo, logo, muito bem vindo à América. Os demais, entretanto, além de uma bateria de exames de saúde, eram obrigados a responder, com rapidez, a um questionário composto por vinte e nove perguntas e exigências, que incluíam: Por que você quer vir aos Estados Unidos? Quanto dinheiro você tem? Onde você arranjou esse dinheiro? Mostre-me. Você tem uma profissão? Você é um anarquista?

\footnotetext{
${ }^{2}$ Tradução livre, como as demais referentes a esse texto.
} 
Se o emigrante falhasse em algum desses testes, era submetido a um novo exame, a um novo inquérito, mais cuidadoso. Além disso, se o indivíduo possuísse um nome que o inspetor julgasse muito complicado, ele lhe era substituído por um "nome americano".

É verdade que apenas 2\% de migrantes, de 1892 a 1924, foram rechaçados. Porém, esse número representa duzentos e cinquenta mil pessoas, das quais três mil cometeram suicídio ali. Ou seja, uma quantia grande demais de esperanças anuladas, de separações, de retornos a um lugar onde já se sabiam infelizes. Aquela era - como reforça Perec - a Porta de Ouro, onde teriam enfim sua chance, onde uma vida nova poderia ter início. Ali: a algumas braças de Nova York. Porém, não era ainda a América. Era "somente um prolongamento do barco/um escombro da velha Europa, / onde nada tinha sido ainda conquistado / onde aqueles que haviam partido / não haviam ainda chegado, / onde aqueles que tudo haviam deixado/nada haviam obtido" (PEREC, 1991, p. $47-48) .^{3}$

Não é de se estranhar que o lugar tenha ganhado o nome de "ilha das lágrimas". "Ellis Island", na pronúncia francesa, pode ser dito como "elisilan", som próximo demais de "exilant" "exilante", "exilador" - para ser ignorado. Era aquele um gigantesco espaço de abandono e de exílio entre o que se deixou e o que se espera.

Interessante a maneira como o gênero documentário atua no sentido de aproximar o espectador dessa memória de errância

\footnotetext{
${ }^{3}$ Semelhante imagem é evocada por Marc Augé, em "Dos lugares aos nãolugares": "O ponto de vista ideal, porque acrescenta à distância o efeito do movimento, é a ponte do navio que se afasta. A evocação da terra que desaparece basta para provocar aquela do passageiro que ainda procura enxergá-la: logo não passa de uma sombra, um rumor, um ruído. Essa abolição do lugar é também o cúmulo da viagem, a pose derradeira do viajante." (AUGÉ, 2008, p. 83). Cabe dizer, no entanto, que o viajante aqui descrito não corresponde ao migrante, para o qual não sobram poses. E a quase-chegada, a interrupção da ilha, pouco tem a ver com o romantismo suscitado pela bela descrição de Augé.
} 
e de exílio: nas palavras de Fernão Pessoa Ramos, "documentário é uma narrativa com imagens-câmera que estabelece asserções sobre o mundo, na medida em que haja um espectador que receba essa narrativa como asserção sobre o mundo." (RAMOS, 2008, p. 22). Perec, juntamente com Bober, constrói uma narrativa unindo narrativas alheias: a do guarda, a dos visitantes do local, a dos entrevistados. O espectador migra por esses fragmentos, como se em um barco. A presença do texto de Perec é consideravelmente pequena: leem-se apenas alguns trechos, em voz over.

Talvez queira Perec fazer com que o espectador realize percurso semelhante ao dele, que, no início do filme, conta ter sido questionado do porquê de dois franceses fazerem um documentário sobre algo, a princípio, tão alheio a eles. E ele responde: "é que eu, Georges Perec, vim questionar aqui / a errância, a dispersão, a diáspora. / Ellis Island é para mim o lugar do exílio, / isto é, / o lugar da ausência de lugar, do não-lugar, do lugar nenhum. / É nesse sentido que essas imagens me concernem, me fascinam, me implicam." (PEREC, 1991, p. 57).

Ou seja, assim como o documentarista une fragmentos de verdade que o conduzem à asserção que muitas vezes transmite no filme, também o espectador é chamado a flutuar nesse espaçointermédio entre partida e chegada. A asserção nesse caso é, portanto, a da sensação de deriva.

\section{III}

Forjando uma continuidade oblíqua ao documentário sobre Ellis Island, chega-se, nesta seção, à "graphic novel" Avenida Dropsie: a vizinhança, de Will Eisner, na qual um dos temas centrais é a influência do processo migratório nas relações interpessoais em uma rua de Nova York. Ali, convivem - muitas vezes, em conflito - holandeses, judeus, italianos, mexicanos, irlandeses, negros, que integram e desintegram a vizinhança, de acordo com o momento histórico e social de sua aparição na 
América - representada ali, metonimicamente, por essa avenida.

O livro não tem outro protagonista senão o espaço, a avenida, e desenvolve-se de maneira semelhante a uma biografia, nesse caso da rua, cuja "vida" é contada desde seu surgimento até sua ruína. Assim introduz essa espécie de narrador:

No início, as casas se agruparam nas intersecções, onde as estradas se cruzavam como numa teia de aranha. Em pouco tempo, surgiram algumas pequenas fazendas que, por sua vez, se dividiram em lotes. Isso era uma evidência nítida do crescimento implacável. A VIZINHANÇA ${ }^{4}$ começou a se formar mesmo com umas poucas e antigas famílias holandesas ainda se apegando às propriedades que haviam herdado. (EISNER, 2009, p. 5)

Nota-se, nesse trecho, a adjetivação do crescimento: ele é implacável. Para ele, não há retorno ou perdão. A vizinhança se desenvolve, portanto, seguindo o modelo da cidade, onde casas e estradas, aos poucos, tornam-se fazendas, que se dividem em lotes. O crescimento, a urbanização, ocorre, assim, à medida que se expande, mas também, e sobretudo, na medida em que se dividem os espaços, em que se compartimentam propriedades e também relações pessoais. É o sentido da linha pontilhada, que estabelece o limite entre um território e outro, um cidadão e outro, na forma de cercas, muros, paredes. ${ }^{5}$

Interessante, entretanto, como, em uma obra em que a delimitação é tão forte enquanto temática, ela não se imponha

${ }^{4} \mathrm{O}$ destaque é do autor. Na realidade, porém, tais palavras são marcadas nessa página - espécie de folha de rosto - por serem o título da obra, que é emoldurado pelo trecho aqui transcrito. $\mathrm{O}$ autor dialoga, portanto, com o recurso tipográfico da caixa alta e com a estrutura tradicional de um livro, em que o título costuma vir isolado em outra página, separado do "texto em si." ${ }^{5}$ A esse respeito, a formação do conceito de urbano, escreve Henri Lefebvre, em "A cidade e o urbano": "[...] o estilhaçamento das antigas cidades permitiu segregações multiformes; os elementos da sociedade são implacavelmente separados uns dos outros no espaço, acarretando uma dissolução das relações sociais, no sentido o mais amplo, que acompanha a concentração das relações imediatamente ligadas às relações de propriedade" (LEFEBVRE, 2008, p. 84). 
enquanto forma. Ou seja, após a pequena introdução supracitada, o narrador praticamente desaparece, restando ao leitor guiar-se sozinho pelas transformações do espaço, pelos desenhos e expressões, pela miríade de personagens que, ao longo de décadas, habitou essa vizinhança.

Tal tarefa, ao contrário do que possa parecer, não é fácil. Will Eisner, conhecido como um mestre dos quadrinbos, apresenta, neste e em outros romances gráficos, a inovação dos recursos na arte sequencial. Em várias páginas, não há, simplesmente, quadrinhos. Há a sobreposição do claro e do escuro, a alternância de preto e branco - únicas cores a compor esse texto -, a perspectiva, a justaposição de quadros, a exploração do movimento pela horizontalidade e pela verticalidade. Eisner logra ainda utilizar-se do desenho em si, do elemento da cena para traçar a moldura, a separação com a cena seguinte: árvores, fumaça, chamas, portas, janelas, postes servem para auxiliar no rumo da leitura, na sequência, no enquadramento, no corte - que é o que impulsiona a narrativa gráfica.

Os quadrinhos, como linguagem, têm a sua especificidade, que não reside propriamente no balão [...]: reside, antes, no modo narrativo visual capaz de agenciar elipses gráficas e espaciais. O desencadeamento de imagens ("congeladas" no tempo e no espaço) será sempre relacional, cuja tessitura significante apontará para a eficácia das relações críticas entre os diversos planos/ enquadramentos de cada série ou história. (CIRNE, 2000, p. 29)

A maneira como Eisner lida com o espaço da página, com os recursos da arte gráfica, intensificam as relações críticas a que se refere Moacyr Cirne. O leitor, na busca pela compreensão da ordem das cenas, acaba tendo tempo de adentrar o espaço relacional, o da reflexão, indo além do que o quadrinho tradicional - no qual as informações, geralmente, já estão prontas, confortavelmente claras e bem traçadas - exige dele. 
Outro esforço é o de acompanhar as inúmeras narrativas menores que se entrecruzam, constituindo a narrativa maior: impressiona a profusão de histórias verossímeis, que se dão a todo o tempo no cotidiano, e que se unem essencialmente pela coincidência do espaço que ocupam. Casamentos, términos, jogos e brincadeiras, brigas, interesses políticos, drogas, preconceito, negócios bem e mal sucedidos, mudanças. No entanto, ainda que se perca de vista o número de personagens cujas vidas são brevemente narradas nesse livro, alguns conquistam maior representatividade. É o caso de Izzy Cash - cujo sobrenome ("dinheiro") antecipa sua verve capitalista -, vendedor ambulante que, em diversas páginas, aparece à margem, movimentando-se pelos cantos das cenas principais, sobre as quais recai o olhar do leitor. Ele é cumprimentado pelos moradores, zombado pelas crianças, ignorado, e permanece impassível, cantarolando "brechó ambulante" e empurrando seu carrinho de mão. Até os quadros em que chega ao banco e, com diversas notas de dinheiro amassadas, compra um dos principais prédios da Avenida Dropsie. Ainda assim, Izzy não permanece em destaque por muito tempo. Da mesma forma que a rua é um organismo movente, modificável de acordo com as pessoas que a habitam, também instável é o foco do leitor pela sequência narrativa. Há personagens que aparecem e retornam muitas páginas adiante; há outros que simplesmente somem. E há aqueles cujas transformações pessoais - que, em grande parte, acompanham seu contexto histórico - surpreendem. É o caso de Ruivo, que se torna um sargento para combater o comunismo, despede-se da namorada dizendo estar a caminho de uma "guerra rápida", e só regressa muitos anos depois. Com as pernas amputadas, sem perspectivas e sem esperança, ele passa a trabalhar para os traficantes da região. Seu desfecho, porém, é posterior, e quase simultâneo ao final do livro: morando em um prédio abandonado, Ruivo - agora chamado de Sarja - persegue, sobre sua tábua rolante, com um revólver em riste, o rato que lhe roubara um pedaço de doce. Não se dá conta de que, do lado de fora, preparam-se para demolir o edifício. 
As ruínas representam, nessa obra, um limite temporal: o dos espaços, que duram enquanto são entendidos e habitados como tal. Os espaços que, embora aparentemente fixos, são tão instáveis quanto as pessoas e suas trajetórias de vida.

A cidade não é apenas um objeto percebido (e talvez desfrutado) por milhões de pessoas de classes sociais e características extremamente diversas, mas também o produto de muitos construtores que, por razões próprias, nunca deixam de modificar sua estrutura. Se, em linhas gerais, ela pode ser estável por algum tempo, por outro lado está sempre se modificando nos detalhes. [...] Não há resultado final, mas apenas uma contínua sucessão de fases. (LYNCH, 1960, p. 2)

A obra de Will Eisner mostra muito claramente esse encadeamento de fases, que geram uma cidade sempre inacabada. Nesse sentido, põe-se em evidência ainda um mecanismo de mutabilidade que são as agências imobiliárias, as quais, contrariamente a seu prefixo de negação, possibilitam a mobilidade. Diversos trechos do romance gráfico enfatizam os contratos de aluguel, de compra e venda, os lucros dos grandes proprietários, as empresas especializadas em negociar itens removíveis dos prédios - como torneiras e vasos sanitários -, os imóveis que se constroem e se destroem. E, sobretudo, as pessoas.

Jacques Roubaud intitula um de seus livros da seguinte maneira: La forme d'une ville change plus vite, hélas, que le cour des bumains. ${ }^{6}$ Do mesmo modo, muitos dos personagens do romance de Eisner, para o bem ou para o mal, permanecem os mesmos, ainda que mudem de par, de emprego, de apartamento. Permanecem preconceituosos ou acolhedores, mesquinhos ou generosos, pedantes ou humildes. Avenida Dropsie: a vizinhança leva a crer, portanto que são as pessoas, no fim, que traçam seus limites, que erguem ou arruínam, que compõem - antes que o contrário - o espaço que habitam.

6 "A forma de uma cidade muda mais rápido, ai, que o coração dos humanos". 


\section{IV}

Os olhos, no entanto, não têm cerca. Não há limite para olhar e, em consequência, para a malícia, para o comentário, para a invasão. As construções da modernidade, os edifícios, embora ampliem o distanciamento pela verticalidade que separa o indivíduo do décimo do morador do segundo andar, acabam por uni-los em espaços comuns - o hall de entrada, os corredores, o estacionamento. Além disso, a configuração das grandes cidades, apinhadas, ausentes de espaço livre, gera a proximidade dos prédios, que se constroem um ao lado do outro, um de frente para o outro. A certas alturas, não chegam os muros. Assim, ainda que se pense protegido pelas paredes, o homem nem sempre escapa das janelas abertas.

Esse é o ponto de partida de Janela indiscreta (Rear window, EUA, 1954), do cineasta Alfred Hitchcock. No filme, o personagem central é L.B. Jeffries, fotógrafo preso a seu apartamento, em uma cadeira de rodas, graças a uma perna quebrada. Dali, confinado à inércia, ele, através de sua teleobjetiva, passa a espionar a vida dos vizinhos do prédio da frente, chegando a descobrir um assassinato. ${ }^{7}$ Revela-se, assim, a possibilidade de intrometer-se no limite do outro, de bisbilhotar, suspeitar, denunciar, criticar uma realidade alheia que se esperava resguardada.

A "poética do edifício" é, não por acaso, bastante profícua tanto no cinema quanto na literatura. Parece haver um encantamento na torre babélica desses moradores incomunicáveis, nos arranha-céus onde muitos se encontram, muitos habitam, e tão pouco de todos se sabe, além dos ruídos fragmentados que resvalam pelas frestas das portas, o cumprimento no cruzar pelos elevadores, o que se supõe pelas janelas indiscretas.

\footnotetext{
${ }^{7}$ Em O filme dentro do filme (1999), Ana Lúcia Andrade analisa essa produção como uma obra metalinguística, em que o protagonista, ao espiar os vizinhos pela janela, refletiria o gesto do espectador em relação ao cinema.
} 
Um exemplo é a obra de Michel Butor, Passage de Milan (1954), em que, baseando-se na ideia do simultaneísmo narrativo, descreve-se a vida de diversos habitantes em um edifício parisiense, que se preparam para uma festa de aniversário. A aniversariante, no entanto, é assassinada. Butor opera, em relação ao prédio, como uma redução da sociedade, uma espécie de "comédia humana" miniaturizada. Nesse sentido, o escritor explora também a relação com os espaços: o apartamento como cubo, cubículo, buis clos.

O acesso à vida alheia é maximizado, no entanto, em outra forma de cubículo: a do enquadramento. No documentário Edifício Máster (Brasil, 2002), Eduardo Coutinho oferece, como define Maria Esther Maciel, um "catálogo da vida ordinária", ao reunir narrativas de 37 dos cerca de 500 moradores de um edifício de 276 apartamentos, em Copacabana. Os entrevistados impressionam pela espontaneidade - como a de uma jovem que relata o primeiro dinheiro ganho ao se prostituir, e a maneira como o gastou, eufórica, indo ao McDonald's com a filha. Surpreendente pensar que, certamente, a maioria desses indivíduos jamais terá tido, entre eles, uma conversa demorada, um momento de desabafo, uma troca de anedotas. Raros saberiam, sequer, o nome de seus vizinhos. Entretanto, confiantes no trabalho de uma equipe de filmagem, indiferentes ao julgamento dos milhares de espectadores que os viriam a assistir posteriormente, abrem-se, escancaram-se diante das câmeras, assim como fazem em relação a seus apartamentos.

Um quadro na parede, um vaso em cima da mesa, um computador na sala, uma tábua de passar roupa, um amontoado de caixas de papelão, os trastes encostados num canto da cozinha, tudo isso adquire uma dimensão quase que narrativa no filme, dado o sabido poder que as coisas geralmente têm de entrar no mundo de nossas referências particulares. (MACIEL, 2009, p. 88) 
As coisas, os objetos são, certamente, motivo de fascínio para Georges Perec. É o que se supõe a partir de A vida modo de usar: romances (1978), em que o autor descreve cada um dos apartamentos de um edifício da rua Simon-Crubellier, número 11, no centro de Paris. Ainda que confessadamente influenciado pelo romance de Michel Butor, há pouco mencionado, Perec produz aqui uma obra ímpar. Muito diferente da sensibilidade engajada de Récits d'Ellis Island, neste trabalho ele atua como um oulipiano ${ }^{8}$ genuíno, ou seja, adepto a cálculos matemáticos, pistas falsas, jogos, longas listas, minúcias, inventários. E, claro, narrativas as mais variadas, que se unem para compor esse aglomerado de romances dentro de um só.

Embora seja difícil delinear o projeto literário do escritor, podem-se dele esperar, em geral,

textos [que] dialogam uns com os outros em torno de uma escritura que privilegia a ambivalência das noções de estrutura e arbitrariedade, regra e liberdade, montagem e desmontagem. A multiplicação do "eu", a enquete sobre a identidade e o desaparecimento, os jogos intertextuais, a reflexão sobre o espaço como lugar de reunião e de dispersão, ilustrada plenamente pela imagem do quebra-cabeças, são aspectos da obra de Perec [...] (ARBEX, 2002, p. 79)

Em A vida modo de usar, a regra começa pela estrutura: Perec escolhe narrar as histórias dos moradores desse prédio projetando o edifício em um tabuleiro de xadrez de $10 \mathrm{~cm} \times 10 \mathrm{~cm}$ e imitando os movimentos do cavalo nesse jogo. Assim, a ordem das histórias contadas não obedece a um alfabeto, uma progressão numérica, mas a um jogo de tabuleiro, sendo cada casa deste correspondente a um apartamento.

\footnotetext{
${ }^{8}$ Referência ao OULIPO - Ouvroir de Littérature Potencielle -, corrente literária formada por escritores e matemáticos, como Georges Perec, Raymond Queneau e Jacques Roubaud.
} 
Além desse jogo, há a forte presença do quebra-cabeças, cuja descrição ocupa todo o preâmbulo. A razão desse prestígio está certamente relacionada ao protagonista, Bartlebooth, herdeiro de uma grande fortuna que, cansado das maneiras tradicionais de gastar seu dinheiro, decide estabelecer para si um desafio, uma tarefa à qual dedicaria toda a sua vida. Ele passa, então, uma década aprendendo a pintar aquarelas; depois viaja pelo mundo, visitando portos, que reproduz em quadros que envia a Winckler. Este, por sua vez, os transforma em quebras-cabeça. Os anos seguintes, Bartlebooth passa montando os puzzles, que, uma vez prontos, são apagados para sempre. A tarefa de Bartlebooth, portanto, visa ao retorno, ao ponto de partida, ou seja, ao nada.

O nome do personagem é uma referência ao Bartleby, o escriturário, de Melville, que, abruptamente, decide que não quer mais executar as atividades que lhe são exigidas, respondendo sempre um curioso "acho melhor não". Há, claro, um questionamento do porquê de se realizar tantos trabalhos, de se esforçar tanto - em diversos aspectos -, sem entender para onde tudo isso nos levase é que leva a algum lugar.

Ao mesmo tempo, o livro é, em si, um quebra-cabeças, que o leitor é chamado a montar. No entanto, da mesma forma que Winckler cria armadilhas para Bartlebooth, também Perec enreda o leitor em várias camadas de narrativas, informações críveis ou não -, detalhes, raciocínios, espelhamentos e, evidentemente, histórias. Cada uma delas tem seu grau de interesse, de destaque, e o leitor perde-se nelas como num labirinto em noventa e nove capítulos. No de número cinquenta e um, por exemplo, narra-se o misterioso assassinato de Lorelei, a qual, por muito tempo, atuara como uma charlatã que, teoricamente, invocaria Mefistófeles para que os grandes figurões com ele compactuassem. Algumas páginas depois, revela-se que um dos motivos do homicídio é o mal-entendido provocado por dois personagens do capítulo XXXI. Em seguida, subitamente, o autor descreve como a dona do apartamento onde morava Lorelei 
contrata um decorador para fazer uma instalação de vanguarda na cozinha. A lista dos objetos escolhidos é extensa, requintada e minuciosa. Contudo, a cozinheira, Gertrude,

não se deixou levar por esses grosseiros artifícios e preveniu imediatamente à patroa que não cozinharia de maneira alguma num lugar como aquele, no qual nada estava no lugar e nada funcionava do modo que ela conhecia. Exigiu uma janela, uma pia de cozinha, um verdadeiro fogão a gás com as respectivas trempes, um tacho para fritar, uma tábua para cortar carne e, principalmente, uma despensa onde pudesse guardar as garrafas vazias, as formas de queijo, os engradados, os sacos de batatas, as vasilhas de lavar legumes e a gamela de salada. (PEREC, 2009, p. 382)

As coisas estão por toda a parte em cada um dos capítulos desse livro, caracterizando seus donos, marcando classes sociais, posses, manifestando descasos ou cuidados. Elas são o sinal desse "homem privado" de que escrevera Walter Benjamin, o homem dos "interiores", que os decora como se fossem sua obra-prima: "O motivo ornamental desempenha nessa casa o papel da assinatura no quadro" (BENJAMIN, 2007, p. 60).

Entretanto, Georges Perec faz questão de mostrar como esse "homem dos interiores" é também um ocupante dos exteriores. Enquanto Marc Augé elege os aeroportos, as estações de trem e de ônibus, os shopping centers como não-lugares da supermodernidade, pelos quais o homem transita sem se estabelecer, Perec nos leva a refletir sobre esses não-lugares dentro do espaço privado, no prédio em que se habita, tais como os porões, as escadas, os elevadores, o hall de entrada. Por ali se movimenta, deixando, inclusive, rastros, vestígios tão benjaminianos. No capítulo LXVIII, por exemplo, enumeram-se os objetos esquecidos pelas escadarias: a foto de uma menina de quinze anos, o rádio-relógio que se destinava ao conserto, um estojo de cigarros de couro da Rússia, várias agendas e carnês, uma máscara de 
carnaval que representa o camundongo Mickey etc. O indivíduo se revela não apenas pelas coisas que possui, mas também pelas que esquece ou se permite esquecer. Sem se dar conta, o homem se deixa pelas escadas do prédio que habita, por esse espaço que mescla público e privado, conforto e desconforto; esse espaço que é, como a mala, símbolo de movimento e repouso. O livro, aliás, começa por ali, pelas escadas.

Certo, a história poderia começar assim, aqui, desta forma, de maneira um tanto lerda e lenta, neste reduto neutro que é de todos e não é de ninguém, onde a pessoas se cruzam quase sem se ver, onde a vida do prédio repercute, distante e regular. [...] Os habitantes de um mesmo prédio vivem a apenas alguns centímetros uns dos outros, uma simples divisória os separa, partilham os mesmos espaços que se repetem ao longo dos andares; fazem os mesmos gestos ao mesmo tempo, abrir a torneira, dar a descarga, acender a luz, pôr a mesa, algumas dezenas de existências simultâneas que se repetem de andar em andar, de prédio em prédio e de rua em rua. Eles se entrincheiram em suas partes privativas - pois é assim que se chamam - e gostariam que nada dali saísse. (PEREC, 2009, p. 16)

Nesse grande edifício, como em todos os outros, cada apartamento é uma casa no tabuleiro, e cada indivíduo é uma peça, contorcida, de arestas complicadas, tentando compor um quebra- cabeça. Nessa justaposição de jogos, tem-se, novamente, a ideia do ponto, do pontilhismo, essa técnica pós-impressionista, em que a figura é representada em minúsculos fragmentos, cabendo ao observador percebê-la como um todo organizado.

A cidade é, assim como uma tela pontilhista, uma imensa composição de pontos que se interceptam, sobrepõem-se, contrapõem-se. O espaço é uma reunião de bairros, de ruas, calçadas, asfalto, casas, edifícios, apartamentos, coisas. Diferentemente, porém, de uma obra de arte, nem todos os pontos permanecem estáticos nesse cenário. Crescem muros em torno das residências que, a 
exemplo das linhas pontilhadas, sugerem o traço de separação entre as propriedades ditas privadas. E, dentro delas, e por todos os lados, movendo-se pelas avenidas em seus automóveis, em transportes aéreos, fluviais, subterrâneos, movimenta-se - e trabalha, e sonha, e habita, e cresce - o ser humano.

Foi por essa perspectiva que se analisaram aqui fundamentalmente essas três obras: pensando-se na amplitude, na modulação, na alternância das vozes nesse diálogo extenso entre o indivíduo e o território que o circunda, seu lugar, o ponto e o traço. O espaço é, assim, uma complexa e fascinante multiplicação de pontos - inclusive, de pontos de vista.

\section{Referências}

ANDRADE, Ana Lúcia. O filme dentro do filme: a metalinguagem no cinema. Belo Horizonte: Ed. da UFMG, 1999.

ARBEX, Márcia. Jogos especulares em Un cabinet d'amateur, história de um museu particular. ALEA: Estudos Neolatinos, Rio de Janeiro, v. 4, n. 1, p. 79-91, 2002.

AUGÉ, Marc. Dos lugares aos não-lugares. In: AUGÉ, Marc. Não-lugares: introdução a uma antropologia da supermodernidade. Trad. Maria Lúcia Pereira. Campinas: Papirus, 2008.

BENJAMIN, Walter. Passagens. Trad. Irene Aron e Cleonice Paes Barreto Mourão. Belo Horizonte/São Paulo: Editora UFMG/Imprensa Oficial do Estado de São Paulo, 2007.

BUTOR, Michel. Passage de Milan. Paris: Minuit, 1954.

CIRNE, Moacyr. Quadrinbos, sedução e paixão. Petrópolis: Vozes, 2000.

EISNER, Will. Avenida Dropsie: a vizinhança. Trad. Leandro Luigi del Manto. São Paulo: Devir, 2009.

LEVEBVRE, Henri. Espaço e politica. Trad. Margarida Maria de Andrade e Sérgio Martins. Belo Horizonte: Ed. da UFMG, 2008. 
LYNCH, Kevin. The image of the city. Cambridge (Mass)/London: The MIT Press, 1960.

MACIEL, Maria Esther. Arquivo de vidas: coleção e biografia no cinema de Eduardo Coutinho. Belo Horizonte: Editora UFMG, 2009.

MELVILLE, Herman. Bartleby, o escriturário: uma história de Wall Street. Trad. Luis de Lima. Rio de Janeiro: Rocco, 1986.

PEREC, Georges. A vida modo de usar: romances. Trad. Ivo Barroso. São Paulo: Companhia de Bolso, 2009.

PEREC, Georges. Récits d'Éllis Island. Paris: Seuil, 1991.

RAMOS, Fernão Pessoa. Mas afinal... o que é mesmo documentário? São Paulo: Senac, 2008.

Filmografia

EDIFÍCIO Máster. Direção: Eduardo COUTINHO. Brasil. VideoFilmes, 2002. 1 DVD (110 min), color. Título original: Edifício Máster.

JANELA indiscreta. Direção: Alfred HITCHCOCK. EUA. Universal Pictures, 1954. 1 DVD. (112 min), color. Título original: Rear window. RÉCITS d'Ellis Island, histoire d'errance et d'espoir. Direção: Georges PEREC e Robert BOBER. INA Films, 1980. 1 DVD (119 min), color. Título original: Récits d'Ellis Island, histoire d'errance et d'espoir.

Recebido para publicação em 13 de fevereiro de 2012 Aprovado em 22 de abril de 2012 